\title{
Association of particles of lipoprotein subclasses with arterial stiffness in a high- risk working population: the Baptist Employee Healthy Heart Study (BEHHS)
}

Muhammad Aziz ${ }^{1,2,3}$, Swetha Gannarapu², Choudhry Humayun ${ }^{2}$, Usman Siddiqui ${ }^{2}$, Khurram Nasir ${ }^{2,4,5}$ and Ehimen C. Aneni ${ }^{2,6^{*}}$

\begin{abstract}
Background: Arterial stiffness is an independent predictor of cardiovascular disease (CVD) morbidity and mortality. A risk factor-independent association of arterial stiffness with traditional lipids has been described extensively, but it is still unclear whether an independent relationship exists between arterial stiffness and particles of lipoprotein subclasses.

Methods: The Baptist Employee Healthy Heart Study (BEHHS) is a lifestyle intervention study examining the effects of web-based programs on reducing CVD risk in high-risk persons. Participants had their brachial arterial augmentation index (Al, a measure arterial stiffness) assessed using the EndoPAT 2000 device. Cardio IQ ${ }^{\text {TM }}$ ion mobility lipoprotein fractionation was utilized for measurement of particles of lipoprotein subclasses.

Results: The population consisted of 182 participants, (74\% women, 49\% Hispanic) with a mean age of $52 \pm 9$ years. There was a significant trend association between quartiles of Al and total cholesterol, HDL-c, large LDL-p, small IDL-p, large IDL-p, and all subclasses of HDL particles (total HDL-p, small HDL-p, and large HDL-p). In logistic regression analysis, only $\mathrm{HDL}-c$, total $L D L-p$, large $L D L-p$, small IDL-p, large IDL-p, total HDL-p, small HDL-p, and large HDL-p demonstrated significant independent association with Al.
\end{abstract}

Conclusion: Several lipoprotein subclasses demonstrate independent significant associations with arterial stiffness. A safe and relatively inexpensive blood test may be useful in identifying subclinical atherosclerosis process in a relatively young high CVD risk population.

Trial registration: ClinicalTrials.gov, NCT01912209. Registered July 31, 2013

Keywords: Lipoprotein, Lipoprotein subclasses, Arterial stiffness, Augmentation index, Employee population

\footnotetext{
* Correspondence: ehianeni@outlook.com

${ }^{2}$ Center for Healthcare Advancement \& Outcomes, Baptist Health South

Florida, 9555 SW 162nd Ave. MAB, Suite 103, Miami, FL 33196, USA

IInternal Medicine, Section of Cardiovascular Medicine, Yale-New Haven

Hospital, New Haven, CT 06510, USA

Full list of author information is available at the end of the article
}

\section{Springer Open}

(0) The Author(s). 2020 Open Access This article is licensed under a Creative Commons Attribution 4.0 International License, which permits use, sharing, adaptation, distribution and reproduction in any medium or format, as long as you give appropriate credit to the original author(s) and the source, provide a link to the Creative Commons licence, and indicate if changes were made. The images or other third party material in this article are included in the article's Creative Commons licence, unless indicated otherwise in a credit line to the material. If material is not included in the article's Creative Commons licence and your intended use is not permitted by statutory regulation or exceeds the permitted use, you will need to obtain permission directly from the copyright holder. To view a copy of this licence, visit http://creativecommons.org/licenses/by/4.0/. 


\section{Research highlights}

- Cardio IQ $\mathrm{IQ}^{\mathrm{m}}$ ion mobility lipoprotein fractionation is a better estimate of particles of lipid subclasses as compared to traditional lipid measurement.

- This study is a step toward determining the true relationship between advanced lipid panel (particles of lipoprotein subclasses) and augmentation index, a measure of arterial stiffness.

- Several lipoprotein subclasses demonstrated independent significant associations with arterial stiffness.

\section{Background}

Arterial stiffness, an age-related irreversible hardening of vessels, is associated with CVD-related morbidity and mortality [1-4]. Arterial stiffness can be measured by augmentation index (AI) and pulse wave velocity (PWV) that represent as measure of wave reflection and arterial stiffness $[5,6]$. AI increases with age and is closely associated with CVD risk factors such as hypertension and coronary artery disease $[7,8]$. It also reflects properties of cardiac performance and overall ventricular-vascular coupling $[4,9,10]$. Brachial artery $\mathrm{AI}$ is a measure of both central and peripheral arterial stiffness $[6,11]$.

The association of arterial stiffness with traditional lipids, such as total cholesterol (TC), triglycerides (TG), low-density lipoprotein cholesterol (LDL-c), and highdensity lipoprotein cholesterol (HDL-c), has been described in cross-sectional studies among high-risk population [12, 13]. However, the relationship between arterial stiffness and particles of lipoprotein subclasses has been rarely studied. The aim of this study is to determine the relationship between traditional lipids and lipoprotein subclasses (measured by the ion mobility technique) with brachial artery AI, a measure of arterial stiffness, in a relatively young high-risk employee population.

\section{Methods}

The Baptist Employee Healthy Heart Study (BEHHS) is a randomized controlled trial examining the efficacy of an interactive internet-delivered program on reducing metabolic risk in an employee population with diabetes and/or metabolic syndrome (MS). The design and selection criteria for BEHHS have been described in detail previously [14]. The results of this analysis are based on the data from baseline visit of the study. The study protocol was approved by the Baptist Health South Florida Institutional Review Board (IRB\#13-028). All participants have provided written consent to participate in the study.

The study measured lipoproteins using the ion mobility technique, a gas chromatography technique that was adapted to measuring subclasses of lipoproteins and has been validated in several studies $[15,16]$. Details of the technique have also been previously described [17]. Augmentation index as derived from peripheral arterial tonometry (endoPAT Itamar Medical Ltd., Israel) is calculated from reflected pulse wave indices. It has shown good test-retest reliability in subjects with metabolic syndrome in previous studies [18]. Because the AI is dependent on the heart rate, it is normalized to a heart rate of 75 . The values provided are gender matched [19].

All statistical analyses were performed using STATA version 13 statistical analysis package (StataCorp LP, College Station, TX) [20]. Continuous variables were expressed as means $\pm \mathrm{SD}$ or median (interquartile range). Categorical variables were represented by frequency and percentage. Spearman Rank correlation coefficients were calculated for each class of lipids with AI (continuous variable). The logistic regression model (controlling for age and BMI) was used to compute the odds ratios and $95 \%$ confidence interval (CI), for an increase in AI with each standard deviation increase in lipoprotein particle.

\section{Results}

The mean age of the 182 study participants was $52 \pm 9$ years with $74 \%$ women $(n=134)$ and $49 \%$ Hispanic population. Across increasing quartiles of AI, there was a significant trend with increasing age and a greater proportion of females. By contrast, BMIs decreased with higher AI (Table 1). HDL-c was the only traditional lipid correlated with AI. Among the lipoprotein subclasses, Spearman correlation showed that small IDL-p, total HDL-p, small HDL-p, and large HDL-p were significantly associated with AI (Table 2). Total cholesterol, large LDL$\mathrm{p}$, and large IDL-p were also significantly correlated with AI. Logistic regression analysis showed that increases in total LDL-p, large LDL-p, small IDL-p, large IDL-p, total HDL-p, small HDL-p, and large HDL-p were significantly associated with increase in AI in the fully adjusted model.

\section{Discussion}

Our study findings, that associate higher LDL particles (total and large) with AI, differ slightly from earlier studies which showed a significant positive association of baPWV (a measure of arterial stiffness) with lipoprotein subclasses of total LDL-p and small LDL-p in relatively healthy population (age 40-49 years) [21] and with very small LDL-p in patients with impaired glucose metabolism [22]. The reason for these varied results among these studies could be due to use of different methods to examine the peripheral arterial stiffness and use of different laboratory techniques to measure the subclasses of lipoproteins.

HDL particles do not follow traditional inverse relationship with $\mathrm{CV}$ risk factors, therefore complicating proper assessment of the relative roles of distinct HDL 
Table 1 Descriptive characteristics of the study population along the quartiles of augmentation index (Al).

\begin{tabular}{|c|c|c|c|c|c|c|}
\hline Variables [mean (SD) or \%] & All $(n=182)$ & Q1 & Q2 & Q3 & Q4 & $P$ trend \\
\hline Age in years (SD) & $51(10)$ & $46.26(9.6)$ & $49.42(9.18)$ & $52.97(9.96)$ & $55.91(7.83)$ & $<0.0001$ \\
\hline$\%$ female & 74 & 41.30 & 77.78 & 82.22 & 93.33 & $<0.0001$ \\
\hline \multicolumn{7}{|l|}{ Race } \\
\hline White & 77.1 & 68.89 & 93.18 & 78.57 & 68.18 & \multirow[t]{3}{*}{0.503} \\
\hline African American & 16.6 & 26.67 & 4.55 & 11.90 & 22.73 & \\
\hline Other & 6.3 & 4.44 & 2.27 & 7.14 & 9.09 & \\
\hline BMI [kg/m2] (SD) & $34.2(6)$ & $37.20(6.3)$ & $35.20(5.7)$ & $33.11(5.3)$ & $31.26(5.1)$ & $<0.0001$ \\
\hline SBP [mmHg] (SD) & $134(15.2)$ & $132.52(12.1)$ & $133.38(13.6)$ & $134.64(16.5)$ & $137.09(17.5)$ & 0.343 \\
\hline $\mathrm{DBP}[\mathrm{mmHg}](\mathrm{SD})$ & $83(9.2)$ & $84.06(8.5)$ & $82.53(8.5)$ & $82.36(9.6)$ & $82.02(10.2)$ & 0.288 \\
\hline Heart rate $[\mathrm{HR}]$ & $73(11)$ & $72.39(11.0)$ & $74.58(9.1)$ & $74.38(12.7)$ & $70.76(11.3)$ & 0.278 \\
\hline Glucose [mg/dL] & $105(37.3)$ & $99.20(27.5)$ & $106.53(46.5)$ & $114(45.7)$ & $100.17(23.5)$ & 0.325 \\
\hline CRP [mg/L] & $6(7.8)$ & $7.24(12.8)$ & $5.81(5.7)$ & $6.26(6.1)$ & $4.08(3.0)$ & 0.355 \\
\hline$\%$ diabetes mellitus & 29 & 21.74 & 37.78 & 31.11 & 24.44 & 0.950 \\
\hline$\%$ lifetime smoker & 34 & 26.67 & 31.11 & 44.19 & 35.56 & 0.215 \\
\hline Physical activity [min/ day] & $1.68(0.5)$ & $1.62(0.5)$ & $1.67(0.5)$ & $1.68(0.5)$ & $1.73(0.5)$ & 0.303 \\
\hline
\end{tabular}

Values are expressed as means \pm S.D. or percentages. BMI body mass index, SBP systolic blood pressure, DBP diastolic blood pressure, $H s$-CRP high-sensitivity C-reactive protein

Table 2 Association of lipoprotein (LP) subclasses with augmentation index (Al) quartiles in study population (expressed as IQR)

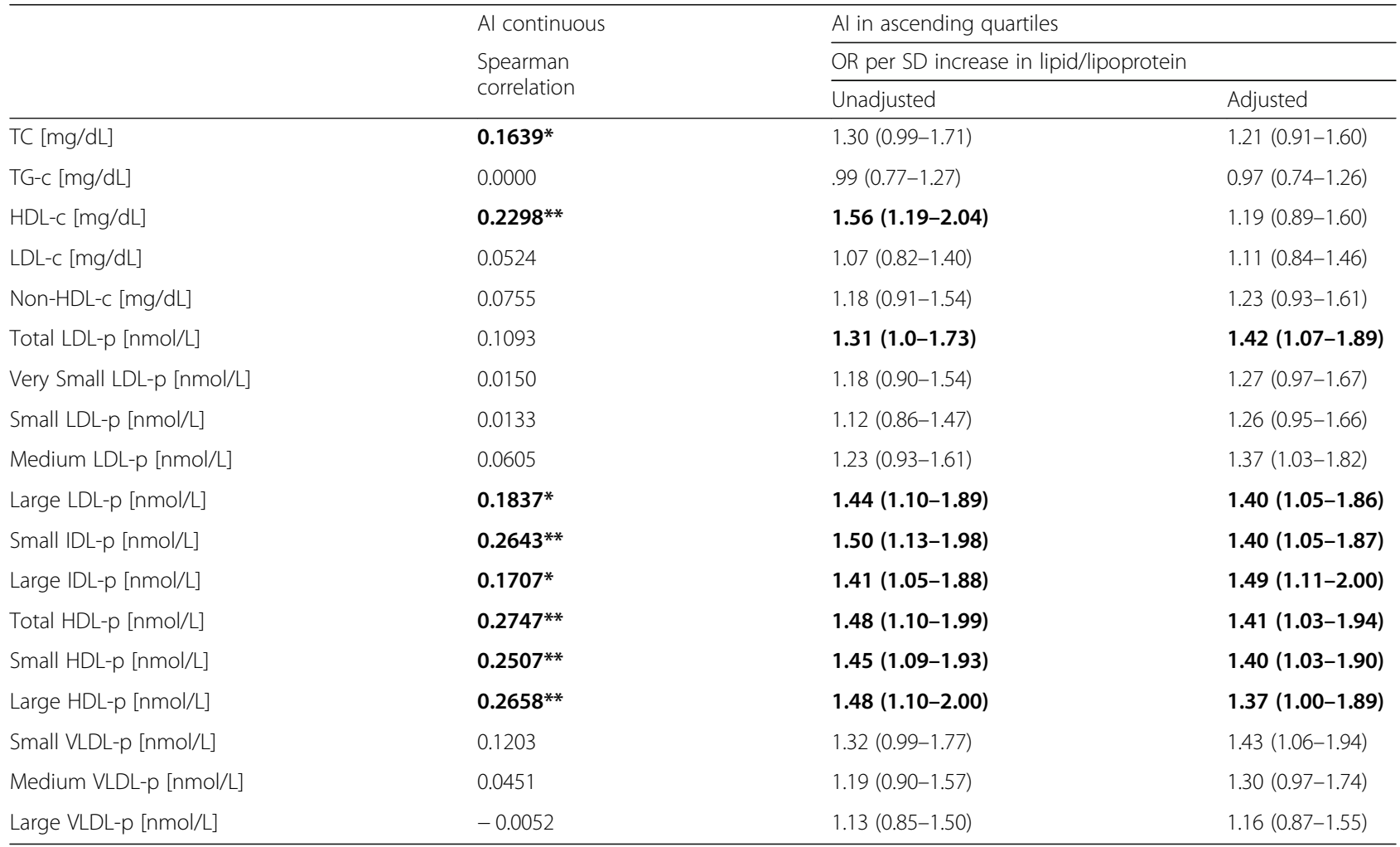

Adjusted for age and BMI. Spearman $\rho=$ Spearman rank correlation coefficient using Bonferroni significance level. Cut-off $p$ value of $p<0.05$ was used for determining significance. Logistic regression models using $95 \% \mathrm{Cl}$ describe the change in Al per SD change in standardized values of lipoproteins. Al augmentation index, $L P$ lipoprotein, $p$ particle number, $T C$ total cholesterol, $T G$ triglycerides, $L D L$ low-density lipoprotein, IDL intermediate-density lipoprotein, $H D L$ high-density lipoprotein, VLDL very low-density lipoprotein

${ }^{*} p$ value $\leq 0.05$

${ }^{* *} p$ value $\leq 0.005$ 
particles in cardio-protection [15, 23, 24]. We discovered that all subclasses of HDL showed a significant positive association with AI in adjusted models. This finding was not unique to our study as previous published papers describe a positive relationship of HDL particles with AI $[21,25,26]$.

Neither triglycerides nor the triglyceride-rich VLDL particles were associated with the AI in our study population. The reasons for this unexpected lack of relationship are not readily clear. Previous studies had shown strong associations of VLDL particles with peripheral arterial stiffness [21]. Our study showed a paradoxical trend toward decreasing BMI with increasing AI. Our study is not the first to report this negative association of obesity with augmentation index [27]. For this reason, we controlled for BMI in the lipoprotein statistical analyses.

Our study is limited by the small sample size which diminishes the study's power. The cross-sectional nature of the study precludes conclusions on causality. The largely Hispanic population also limits the generalizability of the study's findings. We only measured the association of lipids with measures of peripheral arterial stiffness. The inherent variability of the AI as a measure of overall vascular function may indicate that comparison of different methods of AI is needed to predict the association with all classes of lipids.

\section{Conclusions}

In conclusion, our study shows that measures of lipoprotein subclasses are associated with increased peripheral arterial stiffness as measured by AI in a high metabolic risk population. Our study represents a step toward determining the true relationship between lipids and arterial stiffness. Once this relationship is clarified further, pharmacological and lifestyle interventions can be studied in the context of their effect on levels of these lipoprotein subclasses, with the aim of correcting these abnormalities in time and potentially preventing further CVD events.

\section{Acknowledgements}

The authors would like to thank all support personnel for their hard work and dedication.

\section{Authors' contributions}

$M A, K N$, and ECA contributed to the concept and design. MA and ECA contributed to the analysis and interpretation. SG, US contributed to the data collection. $\mathrm{MA}$ and $\mathrm{CH}$ contributed to the table formation. $\mathrm{MA}, \mathrm{CH}$, and SG contributed to writing the article. KN contributed to the critical review of article. MA, KN, and ECA contributed to final approval of article. The author(s) read and approved the final manuscript.

\section{Funding}

No funding
Availability of data and materials

The datasets used and/or analyzed during the current study are available from the corresponding author on reasonable request.

\section{Ethics approval and consent to participate}

The study protocol was approved by the Baptist Health South Florida Institutional Review Board (IRB 13-028). The study was also registered with the ClinicalTrials.gov registry (registration no. NCT01912209). All participants have provided written consent to participate in the study.

\section{Consent for publication}

Not applicable

\section{Competing interests}

The authors declare that they have no competing interests.

\section{Author details}

${ }^{1}$ Family Medicine Center, West Kendall Baptist Hospital, Miami, FL, USA. ${ }^{2}$ Center for Healthcare Advancement \& Outcomes, Baptist Health South Florida, 9555 SW 162nd Ave. MAB, Suite 103, Miami, FL 33196, USA. ${ }^{3}$ Florida International University, Department of Humanities, Health, and Society $(\mathrm{HHS})$, Herbert Wertheim College of Medicine, Miami, FL, USA. ${ }^{4}$ Center for Outcomes Research and Evaluation, Yale-New Haven Hospital, New Haven, CT 06510, USA. ${ }^{5}$ Johns Hopkins University, Johns Hopkins Ciccarone Center for Prevention of Heart Disease, Baltimore, MD, USA. ${ }^{6}$ Internal Medicine, Section of Cardiovascular Medicine, Yale-New Haven Hospital, New Haven, CT 06510, USA.

Received: 7 January 2020 Accepted: 25 February 2020

Published online: 19 March 2020

\section{References}

1. Hung CSLJ, Hsu CN, Chen HM, Tsai RY, Chien YF, Hwang JJ (2009) Using brachial-ankle pulse wave velocity to associate arterial stiffness with cardiovascular risks. Nutr Metab Cardiovasc Dis. 19(4):241-246. https://doi. org/10.1016/j.numecd.2008.07.006 Epub Sep 23. PubMed PMID: 18815016

2. Versari D, Daghini E, Virdis A, Ghiadoni L, Taddei S (2009) Endothelial dysfunction as a target for prevention of cardiovascular disease. Diabetes Care. 32(Suppl 2):S314-SS21

3. Hadi HAR, Carr CS, Al SJ (2005) Endothelial dysfunction: cardiovascular risk factors, therapy, and outcome. Vasc Health Risk Manag 1(3):183-198

4. Laurent S, Boutouyrie P, Asmar R, Gautier I, Laloux B, Guize L et al (2001) Aortic stiffness is an independent predictor of all-cause and cardiovascular mortality in hypertensive patients. Hypertension. 37(5):1236-1241

5. Wykretowicz A, Adamska K, Guzik P, Krauze T, Wysocki H (2007) Indices of vascular stiffness and wave reflection in relation to body mass index or body fat in healthy subjects. Clin Exp Pharmacol Physiol. 34(10):1005-1009

6. Munir S, Guilcher A, Kamalesh T, Clapp B, Redwood S, Marber M et al (2008) Peripheral augmentation index defines the relationship between central and peripheral pulse pressure. Hypertension. 51(1):112-118

7. Fantin FMA, Bulpitt CJ, Banya W, Rajkumar C (2007) Elderly?, Is augmentation index a good measure of vascular stiffness in the. Age Ageing. 36(1):43-48 Epub 2006 Nov 17

8. Weber T, Auer J, O'Rourke MF, Kvas E, Lassnig E, Berent R et al (2004) Arterial stiffness, wave reflections, and the risk of coronary artery disease. Circulation. 109(2):184-189

9. Heffernan KS, Patvardhan EA, Hession M, Ruan J, Karas RH, Kuvin JT (2010) Elevated augmentation index derived from peripheral arterial tonometry is associated with abnormal ventricular-vascular coupling. Clin Physiol Funct Imaging. 30(5):313-317

10. Sharman JE, Davies JE, Jenkins C, Marwick TH (2009) Augmentation index, left ventricular contractility, and wave reflection. Hypertension. 54(5):10991105

11. Woodman RJ, Kingwell BA, Beilin LJ, Hamilton SE, Dart AM, Watts GF (2005) Assessment of central and peripheral arterial stiffness: studies indicating the need to use a combination of techniques. Am J Hypertens. 18(2 Pt 1):249260

12. Zhao W, Gong W, Wu N, Li Y, Ye K, Lu B et al (2014) Association of lipid profiles and the ratios with arterial stiffness in middle-aged and elderly Chinese. Lipids Health Dis 13:37 
13. Freedman DS, Otvos JD, Jeyarajah EJ, Barboriak JJ, Anderson AJ, Walker JA (1998) Relation of lipoprotein subclasses as measured by proton nuclear magnetic resonance spectroscopy to coronary artery disease. Arterioscler Thromb Vasc Biol.:1046-1053

14. Post JM, Ali SS, Roberson LL, Aneni EC, Shaharyar S, Younus A et al (2016) Rationale and design of the Baptist Employee Healthy Heart Study: a randomized trial assessing the efficacy of the addition of an interactive, personalized, web-based, lifestyle intervention tool to an existing health information web platform in a high-risk employee population. Trials. 17(1):1

15. Mora S, Szklo M, Otvos JD, Greenland P, Psaty BM, Goff DC Jr et al (2007) LDL particle subclasses, LDL particle size, and carotid atherosclerosis in the Multi-Ethnic Study of Atherosclerosis (MESA). Atherosclerosis. 192(1):211-217

16. Musunuru K, Orho-Melander M, Caulfield MP, Li S, Salameh WA, Reitz RE et al (2009) lon mobility analysis of lipoprotein subfractions identifies three independent axes of cardiovascular risk. Arteriosclerosis, thrombosis, and vascular biology. 29(11):1975-1980

17. Caulfield MP, Li S, Lee G, Blanche PJ, Salameh WA, Benner WH et al (2008) Direct determination of lipoprotein particle sizes and concentrations by ion mobility analysis. Clin Chem. 54(8):1307-1316

18. Sauder KA, West SG, McCrea CE, Campbell JM, Jenkins AL, Jenkins DJA et al (2014) Test-retest reliability of peripheral arterial tonometry in the metabolic syndrome. Diabet Vasc Dis Res 11(3):201-207

19. McCrea CE, Skulas-Ray AC, Chow M, West SG (2012) Test-retest reliability of pulse amplitude tonometry measures of vascular endothelial function: implications for clinical trial design. Vasc Med 17(1):29-36

20. Stata Statistical Software (2011) StataCorp. StataCorp LP, College Station

21. Vishnu ACJ, Masaki KH, Mackey RH, Barinas-Mitchell E, Shin C, Willcox BJ, ElSaed A, Seto TB, Fujiyoshi A, Miura K, Lee S, Sutton-Tyrrell K, Kuller LH, Ueshima H, Sekikawa A (2014) Group. EJS. Particle numbers of lipoprotein subclasses and arterial stiffness among middle-aged men from the ERA JUMP study. J Hum Hypertens. 28(2):111-117. https://doi.org/10.1038/jhh. 2013.60 Epub Jul 4. PubMed PMID: 23823580; PubMed Central PMCID: PMC3800263

22. Takahashi R, Imamura A, Yoshikane M, Suzuki M, Murakami R, Cheng XW et al (2010) Very small low-density lipoprotein cholesterol level is a determinant of arterial stiffness in men with impaired glucose metabolism. $J$ Atheroscler Thromb. 17(12):1282-1289

23. Goff DC Jr, D'Agostino RB Jr, Haffner SM, Otvos JD (2005) Insulin resistance and adiposity influence lipoprotein size and subclass concentrations. Results from the Insulin Resistance Atherosclerosis Study. Metabolism. 54(2):264-270

24. Jeyarajah EJ, Cromwell WC, Otvos JD (2006) Lipoprotein particle analysis by nuclear magnetic resonance spectroscopy. Clin Lab Med. 26(4):847-870

25. Gallo LM, Silverstein JH, Shuster JJ, Haller MJ (2010) Arterial Stiffness, Lipoprotein Particle Size, and Lipoprotein Particle Concentration in Children with Type 1 Diabetes. J Pediatr Endocrinol Metab 23(7):661-667

26. Paynter NP, Sesso HD, Conen D, Otvos JD, Mora S (2011) Lipoprotein subclass abnormalities and incident hypertension in initially healthy women. Clin Chem 57:1178-1187

27. Tsuru T, Adachi H, Enomoto M, Fukami A, Kumagai E, Nakamura $S$ et al (2016) Augmentation index (AI) in a dose-response relationship with smoking habits in males: The Tanushimaru study. Medicine. 95(51):e5368

\section{Publisher's Note}

Springer Nature remains neutral with regard to jurisdictional claims in published maps and institutional affiliations.

\section{Submit your manuscript to a SpringerOpen ${ }^{\circ}$ journal and benefit from:}

- Convenient online submission

- Rigorous peer review

- Open access: articles freely available online

- High visibility within the field

- Retaining the copyright to your article

Submit your next manuscript at $\boldsymbol{\nabla}$ springeropen.com 